\title{
Margin to Margin: Arts-Based Research for Digital Outreach to Marginalised Communities
}

\author{
Melanie Sarantou
}

Daria Akimenko

Nuno Escudeiro
Postdoctoral Researcher

University of Lapland, Finland

melanie.sarantou@ulapland.fi

Corresponding Author

PhD Candidate

University of Lapland, Finland daria.s.akimenko@gmail.com

Independent Filmmaker. Finland / Italy nmp.escudeiro@gmail.com

This article discusses the artistic activity titled 'Conversations with the edge' that was executed by communities in Australia, Russia and Finland, and curated for an exhibition at the Helinä Rautavaara Museum in Espoo, Finland in 2017. This activity was created in the context of Margin to Margin: Women living on the edges of the world, a larger arts-based research project that took place between four geographical margins: outback South Australia, Finnish Lapland, Russian Kola Peninsula and Namibia. Margin to Margin was a collaboration between artist communities with the aim to explore the relationship between art-making and empowerment of makers living and working 'on the edges'. The aim of the project was to understand the realities marginalised communities face whilst giving voice to these communities by exhibiting their art in various formats, stimulating digital participation and utilising technology for digital inclusion. The purpose of the article is to develop a model that will guide virtual arts-based project mediation for digital outreach in both urban and regionally situated marginalised communities.

Sarantou, M., Akimenko, D., Escudeiro, N. (2018). Margin to Margin: arts-based research for digital outreach to marginalised communities. The Journal of Community Informatics, 14(1), 139--159.

Date submitted: 2018-10-01. Date accepted: 2018-10-15.

Copyright (C), 2018 (the author as stated). Licensed under the Creative Commons AttributionNonCommercial-ShareAlike 2.5. Available at: www.ci-journal.net/index.php/ciej/article/view/1456 


\section{Introduction}

The arts-based research project 'Women living on the edges of the world' (2016-2018), also known as Margin to Margin, aimed to connect through art-making and narrativesharing four geographical margins: outback South Australia, Finnish Lapland, Russian Kola Peninsula and Namibia. The three-year project, that concluded in 2018, was an art and research collaboration between artist communities with the goal to explore the relationship between art-making and empowerment of artefact makers living and working 'on the edges'. The project was realised through a series of art- and storysharing workshops. The mutual empathic response of the workshops' participants, who stem from a wide range of demographics, facilitated the creation of a safe environment for the ones who made art, shared their stories and for their immediate and future audiences. The members of the research group created, discussed, exhibited and shared art with and by communities in Fowlers Bay and Port Augusta in South Australia, Rovaniemi in Finnish Lapland, Murmansk in Russia and Windhoek in Namibia.

The aim of the project was to understand the realities marginalised communities face whilst giving voice to these communities by exhibiting their art in various formats, stimulating digital participation and utilising technology for digital inclusion. Margin to Margin gave voice to peripheral artists and their communities through documentary video, blogs and social media platforms.

The research explored, through art-based approaches, data collection, analysis, presentation and public display of the art, the processes of the artists in their full variety (Leavy, 2015). This cross-continental collaboration viewed the concept of marginality predominantly from the viewpoint of geographical isolation. The challenges of isolation and remoteness took centre stage in the research and art processes. Thus, the project recognised and responded to sensitive topics such as postcoloniality, Indigeneity, marginality and gender issues.

The main findings of Margin to Margin are based on the project's case studies that were conducted in the mentioned geographically peripheral communities. These findings were presented in peer-reviewed papers, book chapters and exhibitions. In all four locations of the research art-making, as well as physical and digital artefacts, served as connective and empowering tools amongst global communities who face various challenges (Miettinen, Akimenko, Escudeiro, Sarantou \& Wallius, 2017). Empowerment came about through the sharing of creative outcomes that communities produced, such as voices, texts and various visual and digital expressions of storytelling and art-making. In addition, these art-based activities permitted artists and makers to negotiate and sustain their identities, while storytelling and personal narratives offered ways for working through particular life challenges and making sense of difficult circumstances (Akimenko, Sarantou \& Miettinen, 2017). The exemplary art activity that will be discussed later in this article well illustrates the strong interplay of identity processes and sense-making in actions of sharing of personal stories and (self-made, or handmade) artefacts, whether sharing occurs through physical, virtual or digital modes. 


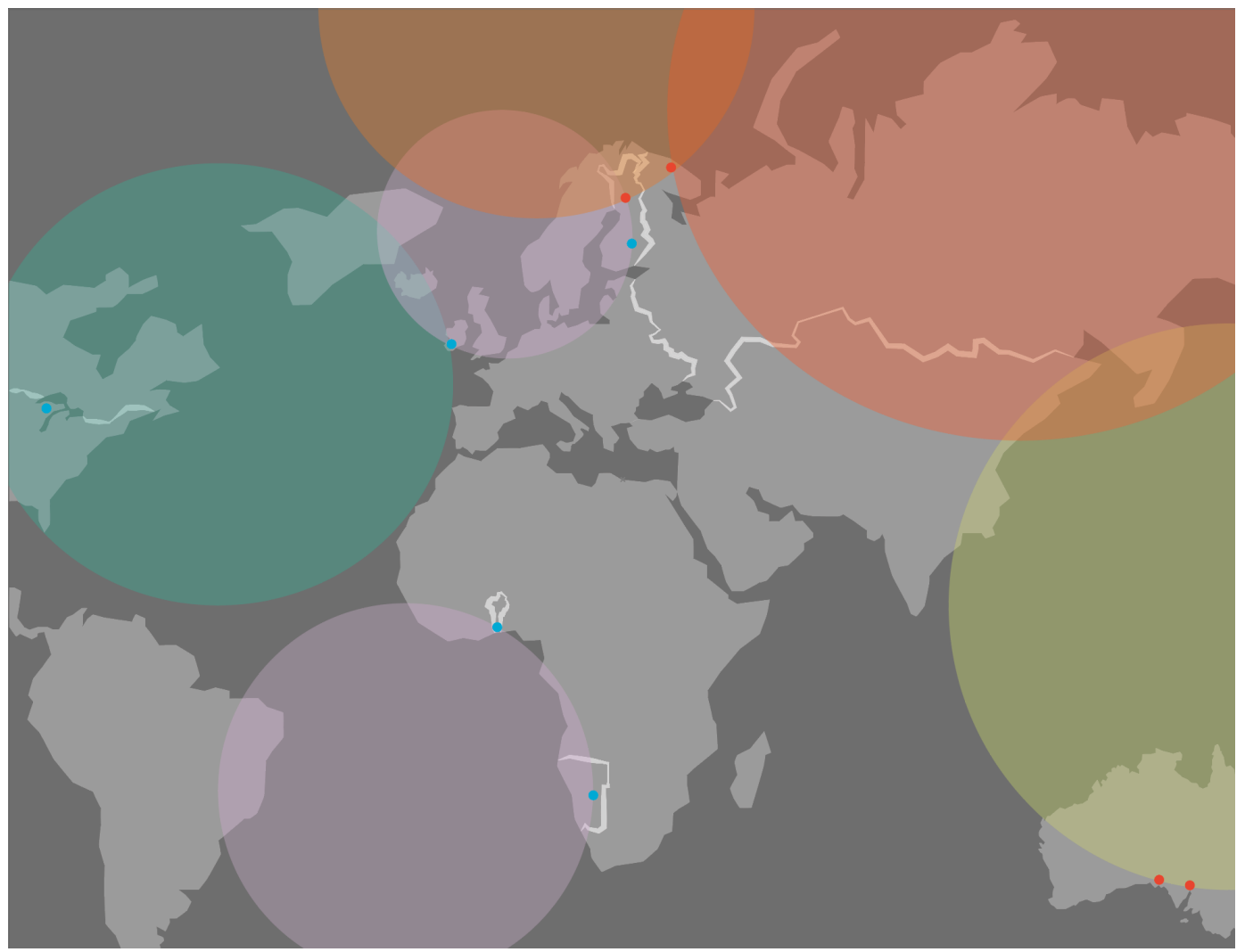

Figure 1. Mapping the workshops and case studies of Margin to Margin.

Additional findings include the key facilitative role of mediation in art-based activities for building empathy between peripheral groups and researchers (Akimenko, 2018; Miettinen, Sarantou \& Akimenko, 2016a; Farkhatdinov, 2014). Mediation is a crucial process that has the potential to empower all stakeholders as it enables them to immerse themselves into, and learn from, local storytelling and contexts. Additionally, new connections will continue to (re)shape during the project, which offers another opportunity for empathic mediation to thrive throughout a project and beyond. It is here that mediation in digitally enabled contexts can make a difference to marginalised communities. The power relations that may develop in digital environments, when stakeholders cannot control the physical movement of artefacts, stories and people, as well as ethical considerations, become vital, calling for rigorous planning, open discussion and plausibility. Through access to key information via valuable platforms the co-creation of social media content, exhibition texts, blog writing, artistic expression and information sharing was encouraged.

Another important finding that is valuable to mediation is the role of intimate bodily spheres, such as laps, that facilitate multiple and complex social and cultural activities, including art and craft making, storytelling and social media participation (Sarantou, 2017). The inclusion of these spaces in workshop and activity planning contribute to the valuable emphatic (re)connections that are needed throughout the lifetime of a project. This focus on intimate spheres and personalised art activities is another key to facilitation of participant engagement as local meanings develop, thus enabling reflection and retrospection when dynamic psychological processes such as narrative 
identities (Ricoeur, 1992; Somers, 1994; McAdams \& McLean, 2013; Akimenko \& Kuure, 2017) come into play during art-making and storytelling.

This article focuses on how human-computer interaction (HCI) can be utilised to develop solutions for virtual approaches to the mediation of art-based research in marginalised communities (Akimenko, Sarantou, Escudeiro \& Miettinen, 2017). In Margin to Margin HCI methods were applied to capture, analyse and represent data such as digitally represented stories, texts and other technological artefacts. Margin to Margin drew on various platforms to enable mediation and the sharing of information, art processes and stories. The art activity that will be discussed later most broadly incorporated all the resources that the researchers and communities used throughout the project.

The activity was approached bottom-up, which required continuous planning, but also for the connective role of improvisatory processes to ensure activity flow and continuation. Arts-based activities, which are often underpinned by improvisation, were not only used to create empathy, but also for problem solving in a complex project that spanned continents. Improvisatory processes stimulated empowerment and community participation despite facing complexities and the limitations of resources (Sarantou, Kontio \& Miettinen, 2017; Sarantou \& Miettinen, 2017).

This article focuses on generating knowledge about the challenges that geographically marginalised communities of practice (Wenger, McDermott \& Snyder, 2002), in this case art-making communities, experience around digital participation. The three researchers who participated in Margin to Margin were also contributing artists. Understanding the challenges for participation in more inclusive research agendas that involve both communities and technologies, can uncover novel strategies that may contribute to digital participation. Digital tools are indispensable for mediating, planning and continuing collaborations between geographically marginalised global communities. This was an additional finding of the project. However, technological platforms need to be ethically implemented and mediated.

This article reflects on the case of intercontinental collaboration aiming to contribute to the understanding of the realities marginalised communities face whilst providing platforms for sharing their narratives. In Margin to Margin this was achieved through exhibiting their art in various formats, stimulating digital participation and utilising technology for digital inclusion. The kinds of digital engagement, both planned and spontaneous, that occurred while taking into account the age and other demographics of the participants is illustrated through an art activity and case study titled 'Conversations with the edge' (hereafter referred to as 'Conversations'). The agency of all of the involved parties in this engagement, from inception through to its end, will be discussed in the sections: 'Conversations with the edge: participatory art avenues for communities' and 'Findings'.

The purpose of the article is to develop a model that will guide virtual arts-based project mediation for digital outreach in both urban and regionally-situated marginalised communities. This article asks: How do we connect to, and coordinate collaborations 
with, geographically remote communities and how do we maintain, in the long term, established empathy with communities of research?

\section{Methodology}

The project drew on a variety of research methods, such as arts-based, ethnographic and narrative approaches. The selected ethnographic methods for the project's field studies were participant observation, diarising, interviewing and video documentation. These methods enabled the researchers to learn from the participants while bringing their own personal backgrounds, work, research and artistic experiences to the field. The data was accumulated over time throughout the fieldwork encounters and during the planning and analytical stages as the researchers' discussions were digitally recorded and stored.

The means of documentation included field journals and digital audio, video and photo, which were key instruments for the project's data collection. Apart from mere data capturing, the documentation aimed to preserve processes and experiences as this adds value in situations of short-term engagements with remote and marginalised communities. Working alongside the communities of participants and creating shared experiences and spaces called for possibilities to revisit and reflect upon experiences by all of the involved parties. When documenting the encounters aesthetically, as well as ethically and factually, viewers, participants and researchers can experience the occurrences in the field. The digital documentation tools that were used are discussed in 'The use of digital tools to connect to communities', alongside those that were applied in different stages of the project.

Arts-based approaches were applied in two different ways throughout the research encounters. The researchers acted as mediators by creating spaces for the research participants to produce artworks and tell their stories, but the researchers also took on artist roles to produce, curate, and mediate individual and group artworks. The research participants shared and implemented their knowledge of traditional craft, visual and media arts, while they engaged in peer-to-peer learning with their colleagues and the researchers in a collective manner.

Radical inclusion (Akimenko, 2018) was adopted as an ethical approach in Margin to Margin. This approach focuses on working with communities and was formulated by one of the authors of this article in her doctoral thesis (currently submitted for preexamination). It derives from bell hooks' (1989) notion of 'radical openness' that finds empowerment through complex and whole experiences, whether they are positive or traumatic. Radical inclusion is a model that 'aims to create a space and time for an open dialogue through the multiplicity of voices and perspectives' (Akimenko, 2018). It accounts for all the unfamiliar and unexpected field situations including potential conflicts. The researchers do not dictate, but rather, include research events as they unravel. This approach also derives from Soja's (1996) concept of Thirdspace that aims to move away from dichotomies (such as self-other, here-there) through the inclusion of a third (or an endless number of) components. 
Another methodological approach to this article includes the case study titled 'Conversations'. This art activity was one of the exemplary activities of Margin to Margin as it well illustrates the ethical approach of radical inclusion. While the project's community interventions in the mentioned peripheral and remote areas included more than eighty, predominantly female, participants (between the ages of 20 and 92) whose art-making and storytelling were observed, photographed and video documented, the case study included forty, predominantly female, participants (between the ages of 20 and 72). This article's analytical approach will draw on the reflections, documented notes and digitally recorded group discussions of the researchers, as well as the participants' recorded interviews, video messages and artwork.

\section{Digital mediation and facilitation}

The approach of radical inclusion was applied in the analytical stage in order to accommodate the collected narratives holistically and represent the project in its full complexity. The researchers used ethnographic and narrative approaches to analyse the processes, artefacts and stories that were shared amongst the communities. This enabled the curatorial and exhibition processes, whether these were conducted locally, virtually and/or digitally, so that meanings could be understood, established and shared. These processes took place continuously throughout the conceptualisation and planning of the project, the fieldwork, and subsequent processing and curation with the aim to communicate to wider audiences outside the project. Throughout these processes the researchers engaged in ongoing reflection, while simultaneously facilitating the processes of the participating artists and defining ethically-sound strategies for presenting the art and voices of the participants to the audiences.

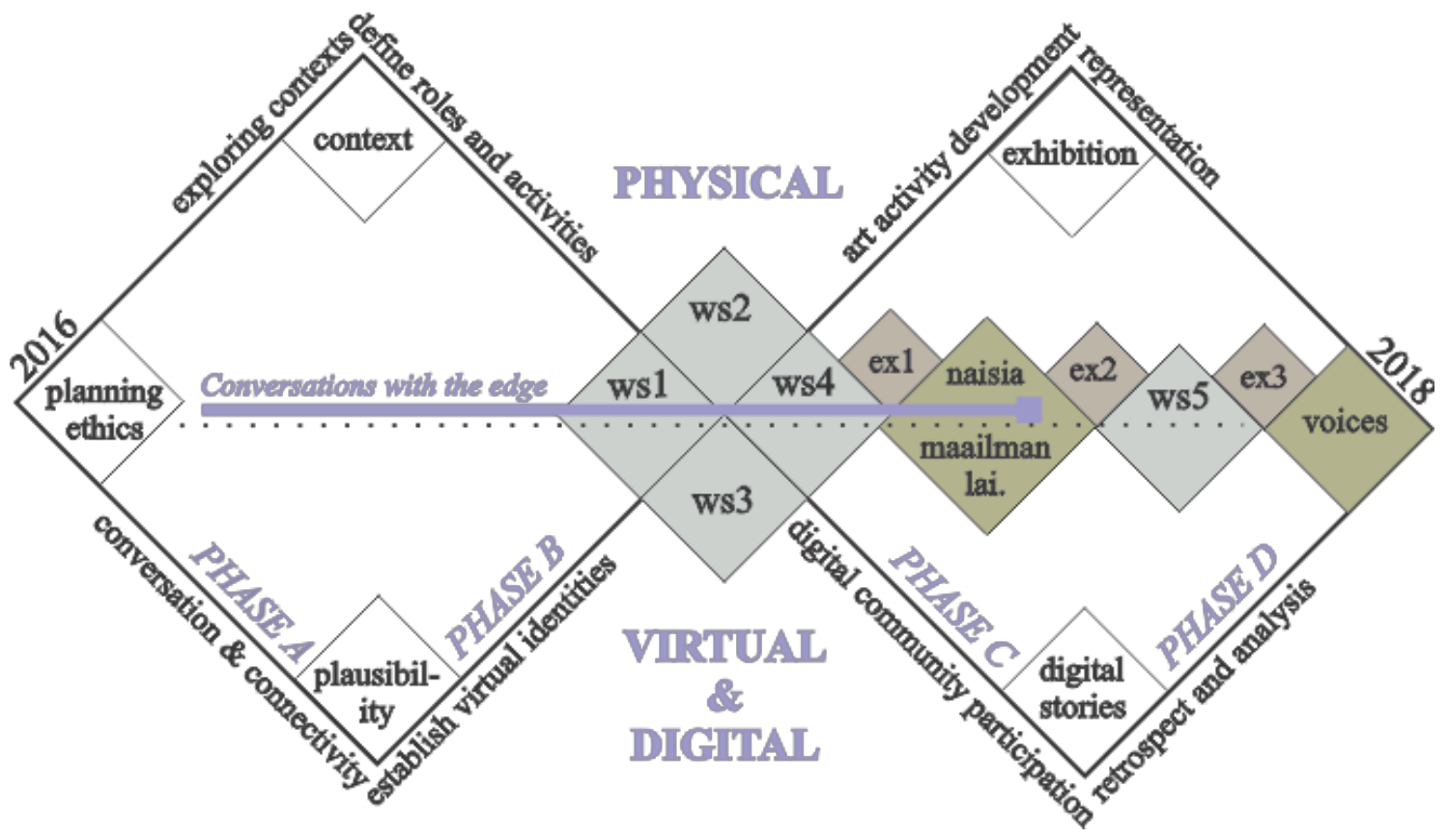

Figure 2: The illustrated role of digital participation and mediation in the project Margin to Margin. 
The diagram (Figure 2) illustrates how the project's researchers facilitated and managed the project, despite often being dispersed over three continents and four countries, from its development to its end. The diagram shows two large diamonds in which smaller diamonds are placed to indicate key activities of Margin to Margin. The top of the diagram represents physical actions and events, while the bottom shows the virtual and digital activities. Thus, the project was built on strong virtual and digital processes and tools. The large diamond on the left in the mediation diagram represents strong preparatory and explorative processes that were underpinned with ethical approaches to research and community, as well as arts-based approaches. The large diamond on the right represents the developmental processes in mediation, for example the representation of communities and their art through digitally produced stories that were exhibited in galleries and museums, as well as via documentary video ${ }^{1}$ and blogs ${ }^{2}$.

The centre line of the diagram (Figure 2) does not represent an accurate timeline of the project as some activities took longer than others. The project planning and funding applications started in September 2015. The planning included a virtual introduction meeting via Skype, community consultations in the various locations and Human Research Ethics Committee (HREC) applications in South Australia and Finland. The project implementation kicked off in 2016. The three researchers were professionally practicing artists whose roles were supported by two further artists, one in film and the other in visual art.

In the centre of the two large diamonds are indicated the four workshops that took place between October and December of 2016. The five significant workshops are the grey diamonds, shown as ws1 to ws5, which took place as follows: Workshop 1 (ws1) in Fowlers Bay, South Australia; Workshop 2 (ws2) in Port Augusta, South Australia; Workshop 3 (ws3) in Rovaniemi, Finnish Lapland; and Workshop 4 (ws4) in Murmansk, Kola Peninsula, Russia. Workshop 5 (ws5) was hosted later in 2017 in Windhoek, Namibia. The moss green diamonds represent the two larger exhibitions. The first was 'Naisia Maailman Laidalla', which means 'Women from the edges of the world' (hereafter referred to as 'Naisia')3, was hosted at the Helinä Rautavaara in Espoo, Finland. The other exhibition was 'Voices' 4 , which was hosted at the Port Augusta Cultural Centre - Yarta Purtli in South Australia. The 'Voices' exhibition also marked the end of the project (2018). The three small diamonds indicated as ex1, ex2 and ex3 were smaller art exhibitions that were locally curated and managed. One collection of work was exhibited at the Platform Gallery in South Australia, one at Arktikum in Rovaniemi, Finland, and the last at the Hämärä Gallery at the University of Lapland in Finland.

\footnotetext{
1 https://vimeo.com/margintomargin

2 https://margintomargin.com

3 https://www.kulttuuriespoo.fi/fi/event/10897-naisia-maailman-laidalla, http://tinyurl.com/naisiahelina

4 www.margintomargin.com/voices
} 
The main activities of the project, as discussed above, mostly consisted of both physical, in situ, as well as complex digital activities that had to be taken care of due to the location of the research team in various global settings. However, this dispersed situatedness of the researchers had an important impact on the selection of the participating communities. A strategy was selected that ensured that at least one of the researchers was familiar with one of the participating communities. This familiarity was defined as either positive and previously established connections, knowledge of culture and language, paired with well-established insights into the local contexts of the participants. This strategy was successful as it ensured a rigorous project design because researchers were able to draw on past experiences during the fieldwork.

However, the downside of this approach also was that an over-dependence on one researcher in a given context resulted in much pressure being placed on one member of the team in that context. For example, in Russia the team had to heavily depend on the language abilities of one of the researchers (Akimenko, Sarantou \& Miettinen, 2017), while in Fowlers Bay another researcher had to focus most of her time taking care of logistics and the practical arrangements of the large group of participants. In Fowlers Bay, South Australia, the sensitive cross-cultural contexts that the researchers faced, with forty-two participants from at least a dozen different cultural and language groups who gathered from all over the world, including Indigenous groups from South and West Australia, placed much pressure on the 'local' researcher and the South Australian art project management team.

The physical actions and events, mostly indicated in the top of the diagram (above the broken line) constituted the process that can be followed in the diagram from Phase A to D: (a) exploration of contexts, (b) definition of roles and activities, (c) development of art activities, and (d) representation of stories, art and communities. The virtual meaning-making process, which can be followed below the broken line from Phase A to $\mathrm{D}$ is: (a) establishing connectivity and on-line conversation, (b) establishing virtual identities (through social media, blogs, website ${ }^{5}$ ), (c) community participation through digital platforms, and (d) retrospect, analysis and new knowledge production (virtual storytelling). The digital platforms that offered the researchers, artists and communities many possibilities for knowledge and experience sharing were Skype, Google Docs, Dropbox, messengers (especially the use of group messages amongst some of the communities became popular as the project progressed), the project website, blogs and various social media sites.

Communities shared ideas about art processes, how they used materials and developed their artworks or concepts. The researchers shared sometimes complex processes such as project planning and design, ethical research and funding applications, art planning and making processes, exhibition design and coordination, knowledge development and analysis, and dissemination of research data. All research meetings were documented digitally and stored in Dropbox where they were accessible for further use and referencing. The importance of digital plausibility (illustrated in the first large diamond) through information sharing via enabling platforms was well-managed since the 
inception of the project. A suitable virtual communication and project structure was adopted, while the ethical approach of radical inclusion (Akimenko, 2018) was embraced. Trust, respectful conduct, the acknowledgement of personal identities and on-time delivery were the values that the team adopted early on (Weick, Sutcliffe \& Obstfeld, 2005; Alavi \& Tiwana, 2002; Curşeu, Schalk \& Wessel, 2008). The ability to respond to salient cues through interpretation, explanation and application in virtual and local contexts (Weick, 1995; Nemiro, Beyerlein, Bradley \& Beyerlein, 2008) strengthened the trust and mutual support amongst the team. With a solid digital filing system in place, the ongoing production of large numbers of digital video, photo, and other data files enabled analysis, transcription, knowledge production and representation of the digital narrativity processes that made up many of the digital activities later in the project. For example, many videos were produced and translated into English, Finnish and Russian.

Additional representational considerations also resulted in large amounts of digital information as various exhibitions were developed that had unique aims. The 'Naisia' exhibition, for example, was executed for an ethnographic museum and so the stories of women from the edges of the world were in focus. In this exhibition, their stories covered meaning-making and identity processes in relation to place, social, cultural and natural environments. Later on the 'Voices' exhibition focused on more personal works of artists and art communities, narratives of fulfilment and happiness. All these stories and many of the art processes were digitally captured and processed. In the case of the last exhibition, for example, the voices of all fifty participating artists were represented on the website.

\section{The use of digital tools to connect to communities}

The participating researchers aimed at co-creating artistic work with the participating communities. Based on the collected materials and artwork, storytelling was captured through documentary video and research diaries. The researchers mediated processes with the communities to make sense of these materials through curatorial practices. A common goal sought by both the participating communities and the researchers was to ethically produce and reproduce materials that could be presented to local, global and online audiences. Apart from many other processes, the artworks and their making processes, story-making and telling, were carefully captured through video due to the vast possibilities this medium offers.

The main activities of the workshops of Margin to Margin consisted of art-creation that was based on personal life-stories that were narrated by the members of the involved communities. With the aims of documentation, data-collection and the display of artistic results, the researchers resorted to digital tools, such as photo, video and audio recordings, to capture the narratives that underpin the artworks. In addition to the material aims of the documentation, the researchers found that the use of video cameras also served as a catalyst for narrative sharing as they reinforce 'a sense of commitment or engagement with the immediate, intimate, and personal as it occurs' (Nichols, 2017, p. 136). The results were fruitful for the objectives of the research. The moments of sharing and empathy that were created between the participants and artist-researchers 
came about due to the retelling of personal narratives in the field and in later phases of the project.

During the fieldwork, the researchers had several objectives for digital documentation:

1. creating outputs immediately and 'on the go' for the sake of, and to instil a sense of, inclusion for the communities;

2. the transparency of online representation of the participants and communities and offering opportunities for contemplation and discussion about the digital outputs;

3. to instil trust and create empathy;

4. to create physical and digital outputs that were shared with the participants;

5. the creation of audiovisual works for further video editing and creation, analysis and dissemination; and

6. providing opportunities for the withdrawal of consent, especially in cases where the participants did not control digital video editing processes.

Thus, digital documentation acted in tandem with social media and online tools as the project blogs and photo snapshots were immediate and shareable outcomes alongside the video field journals that were ongoingly and skilfully edited 'on the go' in South Australia, Rovaniemi and Murmansk while the fieldwork and workshops unfolded. In all of the workshops the video documentaries were shared with the communities with the aim to reciprocate the time they had invested in the workshops. The final exhibition outcomes of audiovisual documentation were shared not only with the exhibition audiences, but were brought back to the participating communities through online platforms and social media (such as Facebook and Vimeo) to enjoy and reflect on the research encounters.

Throughout the fieldwork, 5 hours 42 minutes of interviews with 54 research participants and four artist-researchers were audio- and video-recorded in four locations (Fowlers Bay, Port Augusta, Rovaniemi, and Murmansk). The sampling of the project was almost twice this size, but some participants only contributed artistic outcomes, whilst others shared only narrative data or both. Additionally, 22 audio-interviews that lasted between 7 and 29 minutes were conducted with randomly selected participants in all the workshop locations. Apart from the interviews, other unedited video footage amounted to 5 hours 56 minutes of the making and arts-based processes and 13 hours 7 minutes of contextual observation (travelling, walking, the 'feeling of place').

Two examples of using digital platforms for including the remote communities are worth mentioning here. Firstly, the 'Voices' exhibition, the key exhibition of the Desert Fringe Festival in Port Augusta during March 2018, attempted to recreate the display and the 'feeling' of the exhibition for the contributing artists from Rovaniemi, Murmansk, Windhoek, Helsinki and Berlin, many who were not able to attend in person, but also for those who are geographically and economically marginalised. This was achieved through placing photographs on the website ${ }^{6}$ of the artists and their

$6 \quad$ www.margintomargin.com/voices 
artworks, as well as textual and audio messages that narrated the stories of the artists and their work. The interactive website increased the shareability of the exhibition to external audiences. An artist talk was organised via Skype for the local audience in Port Augusta during which Finnish artists conversed with their South Australian colleagues and audiences.

Secondly, the artistic activity, and case study of this article, 'Conversations', resorted to video in a different way. This activity was initiated by the enthusiasm of the research participants themselves. Their wish was to send video messages between the different communities with the aim to present groups, themselves as individuals, their cultural backgrounds and information about their environments. The participants' objectives were also to send positive wishes and thoughts to one another. This activity is introduced in the next section.

\section{Conversations with the edge: participatory art avenues for communities}

The case study 'Conversations' presented multi-layered artefact-making and narrative outcomes from February 2016 until August 2017. However, the activity was not initiated by the researchers, but by one of the participating communities in Margin to Margin. This community, the Fibrespace Incorporated textile art group (hereafter referred to as Fibrespace), is dispersed over regional South Australia. This activity project set out to attract a reactive response from other global communities by sending personal handmade textile artefacts or notes to artists in Lapland and elsewhere. The first virtual contact between Fibrespace artists and the researchers of the project had happened months before a meeting in Port Augusta during October 2016. The artists' initiative to reach out to their Finnish counterparts had resulted in a collection of work, mostly textile art, which was titled 'Conversations with Lapland'. The work included a set of stories and artefacts telling about the individual artists and their art practices, interests, homes, families, lives and connection to the South Australian natural environment. One Fibrespace member introduced the group:

Fiberspace is more a textile-based group. It is a group of people who meet three times a year. And in different places just to foster their interest in textile arts, or really I think it is just creative thinking as much as anything. We just love to get together to see where our creative thoughts might take us. But I really quite enjoy that lurching into something new and seeing where it takes you and being prepared to make the most of whatever situation that comes my way. (Participant, Port Augusta, 2016)

The textile artist group created a selection of artefacts, from February until July 2016, which were then presented by the researchers to the participants in Rovaniemi and Murmansk during December 2016. The response to the Fibrespace artists was somewhat unexpected. Not only artefacts were shared, but also video messages were initiated in Rovaniemi in which spoken messages were captured. These videos were then sent from community to community. The receiving communities also started to contribute video messages in return to the ones they received. The narratives of the 
participants, those that were captured in both the artefacts and video messages, were constructed around the notions of belonging, home and place. Specific artefacts and messages strongly narrated personal identity. Through these artefacts, video messages and their making processes, participants reflected on their personal margins and how they cope with, or overcome them.

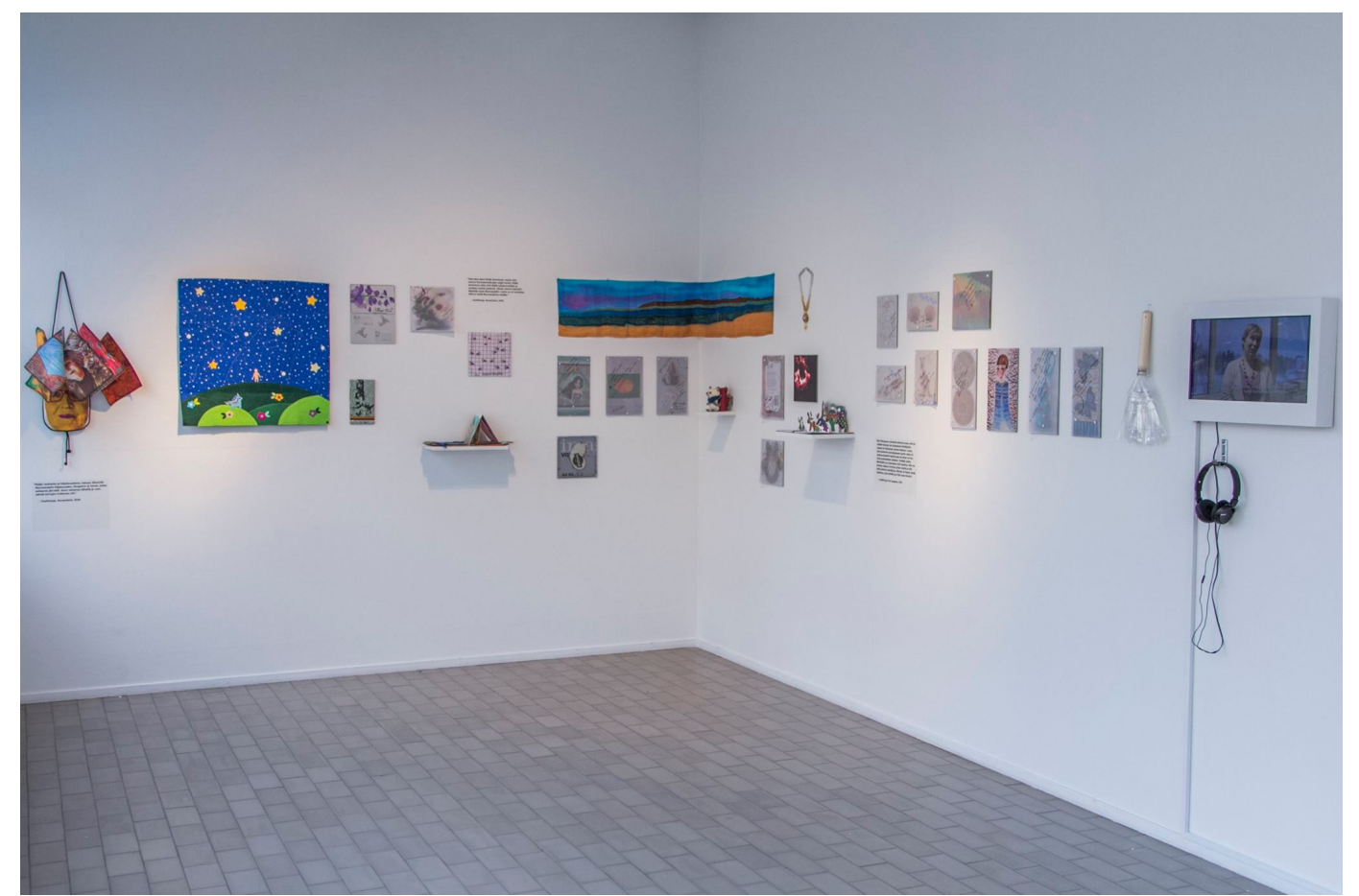

Figure 3: The display of 'Conversations' during the 'Naisia' exhibition at the Helinä Rautavaara Museum in Espoo, Helsinki. Photo credit: Daria Akimenko.

The larger body of work, that consisted of artefacts, videos, photographs and written field notes, later was titled 'Conversations with the edge' (Figure 3). This collaborative work was curated by the authors for the exhibition 'Naisia'. The exhibition ran from 6 September 2017 until 7 January 2018. One of the researchers took care of the artefacts' display and representation of their underpinning stories. She also mediated the process of artefact exchange between the artists, which was documented in field notes. Another was responsible for editing audiovisual data into video artwork that represented in a holistic way the encounters and sending of messages 'from one edge to another'. The third researcher aided both colleagues in the selection and curation of the vast amounts of digital and physical materials. The activity instigated links between remote communities 'on the edges' through the sharing of a collection of stories and artefacts between them. This alternative process of sharing, collection, reception and curation of the artefacts and video messages was a challenge to curate. The diverse artefacts and video messages that constituted 'Conversations' had to be collected and brought together into one space as one narrative, yet the curatorial team did not want to compromise the voices of the individual participants and their communities.

The act of making, collecting, sharing and curating happened over many months. Illustrated in Figure 2 is the approximate duration of 'Conversations' in relation to the project activities, which indicates that the activity commenced in the first quarter of 
2016 when the Fibrespace group met and decided to reach out to unknown artists in Lapland, and ended with the 'Naisia' exhibition. The idea to connect to Lapland came about due to a suggestion from one of their members, and one of the researchers in this project, who had previous connections with artists in Finnish Lapland. The Fibrespace group took on the challenge without hesitation and decided to produce artefacts that would be sent to Lapland with the aim to introduce themselves as individuals, but also as a textile artist group. This gesture was keenly adopted by the Lapland artists. As a further result, the Fibrespace artists agreed to participate in Margin to Margin.

Fibrespace invited a group of Lapland artists and the researchers to participate in a workshop in Port Augusta at the Platform Gallery during October 2016. The workshop consisted of a textile installation that was constructed with Life Story Mandalas at the Platform Gallery (Miettinen et al., 2016a), art-making, peer-to-peer learning and story sharing activities. One artist from Port Augusta shared:

I came to Port Augusta in my first teaching job, from Adelaide. And I have been here ever since, and I married a local boy who swept me off my feet, I guess. In those days it was kind of an outback town and there wasn't a lot of cultural aspects to it. So, I have really felt I needed to connect with something in the arts. Because I come from that. My parents and my grandparents were quite into art. So coming here then finding it very difficult to find like-minded people, I had to gravitate to the local art group. Then I started to find people who spoke my language. (Participant, Port Augusta, 2016)

However, the idea of the sharing of artefacts from Fibrespace continued after this workshop when Lapland artists reacted in the Rovaniemi workshop by making artefacts and digital greeting messages that were returned to Fibrespace, but also passed on to Murmansk in Russia. This was also an initiative that was improvised in Rovaniemi, with the aim to create connections between the participating global communities. During the workshop in Murmansk, the artist community there reciprocated in a similar fashion by sending handmade artefacts and video messages to both communities in Lapland and Australia. One participant from Murmansk shared her ideas about her handmade artefact that was sent to Fibrespace:

It is not something just written like 'Hello' and 'How are you', because you can do it on Facebook. If people receive something material that you made with your hands it is different, because you send your warmth to another person, and maybe your love or the mood you were in while you made it. From this bookmark I made the person who received it will remember me while reading. (Participant, Murmansk, 2016)

For the communities the sense of connecting with others was an identity-shaping process in itself, as the communities displayed and communicated their specific identities to render themselves 'different' or 'same'. Identity processes included the acts of mediating, collecting, and participating as makers, senders and receivers of artefacts and messages to strangers with a common passion: art-making. 


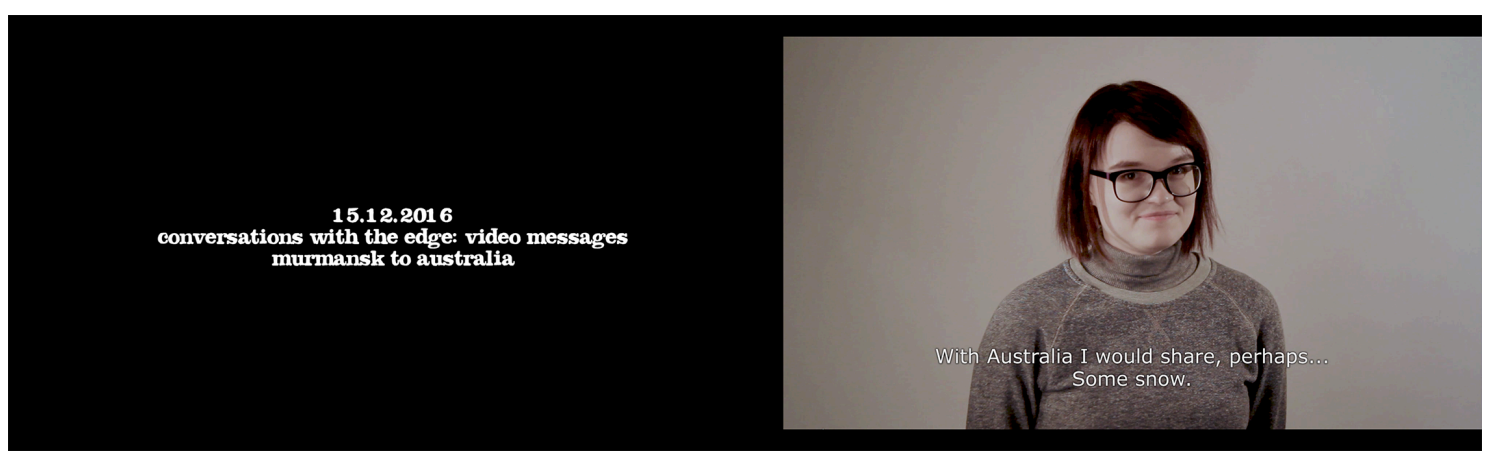

Figure 4: An example of a video message to Australia: a narrative via video interview in Murmansk.

The two documentary artists and co-authors of this article, mediated the process of digital message sharing (Figure 4). This involved time-consuming filming and editing, transcriptions and translation into the three relevant languages: English, Finnish and Russian.

\section{Findings}

The transcriptions and translations were analysed through open coding, which means to determine category systems or headings under which data is grouped (Burnard, 1991; Berg, 1989). It became clear that the messages that were shared by participants carried similar themes that related to identity narratives and expressions about place, belonging, feelings, their environments and what they appreciated most within their local contexts. The following narratives illustrate the connections that the participants sought from creative communities and individuals around the world, through narratives as means for sense-making and identity formations (Sarantou, 2014).

Memories, sense of atmosphere and location and place were strongly narrated through the digital messages related to participants' memories and experiences of places, such as the moods and atmospheres that surround them and which identities render them as unique. One participant said: 'A lot of time in the year it is dark here, and the city is decorated with little lights. When I was small and used to come to Murmansk, those lights used to really mesmerise me. And nowadays I still like them a lot.'

Many participants expressed memories from their homes where they currently live, or the places, cities and countries that they identified with at some stage in their lives. One participant remembered Kuopio in Finland and said: 'I think I would like to bring the atmosphere, the silence and the boats which are whistling there on the lake. I live on the harbour and there are those boats which go in the lake side.' Another participant stated: 'All these beautiful things that we have now in the winter in Portugal, that are tendentiously sunny days that I wish I can bring a little bit of sun to your dark days that you are living through now.'

A participant that was born in Thailand, but who travels regularly reminisced about the memories and buzzing atmospheres of the places she knows and has lived in: 'Maybe the momentum of living in Bangkok. One thing happens after another. Like in Rome. 
So maybe that can give the rhythm in there as well. Going at a fast pace and something surprising happening all the time.' An Australian participant's memories were tied up in the festive atmospheres of one of the states when she said: 'From Australia I would probably like to bring some festivity from there and I think the nicest festive substance that you can have from South Australia is the wine. Because South Australia makes beautiful wine,' while a Russian participant added enthusiastically: 'We have a wonderful café called Youth here. Besides, our city is young with many talented and creative people. I would like that it is the same not only here, but everywhere.'

A sense of environment and natural phenomena that shape identities of place was narrated by many participants from the Arctic who identified with the weather conditions of cold and snow, which they understood to be a harsh contrast to the hot Australian summers. Seven participants from Murmansk made references to the snow and cold when they answered the mediator and video artist's question about what they would like to send to the artists in Australia. Some replies were: 'A bit of frost for them to feel more vigorous. It's our most available commodity, therefore...' Additional comments included 'To Australia I would send snow, lots and lots of snow'. Also, 'I would take all of our snow and transport it there, also for us to have less of it' and 'Do you think they would appreciate if I wish them some snow?' Additional comments from participants on this topic were: 'With Australia I would share, perhaps, some snow'; 'Some fresh breeze from Kola Gulf'; and 'Some snow.'

Additional references to the Arctic environment, thus also to Arctic identities, were 'For Australia I would wish to experience how our polar night feels.' More references to the Northern lights included: 'And of course our Northern Lights. I wish that everyone who has not seen them saw the Northern Lights at least once'; 'To Australia I would send Northern Lights. One can talk about its beauty a lot, but you have to see it for yourself!'; and 'Yes, to try something new is always good. I would also wish to everyone to see our Northern Lights, because they are mesmerizing.'

There were also references made to the many flies in Australia. Stating that it was 'a problem' perhaps indicates that the participants in Murmansk had difficulty identifying with the many flies, thus rendering, in an amusing way, identities of 'us' and 'other'. One participant introduced the topic as follows: 'I've heard that there is a big problem with flies in Australia' while another continued: 'I wish them to solve it and to live comfortably without flies.' One participant offered a solution to the 'problem' and suggested what she would like to send to the artists in Australia: 'I guess... lots of sticky tapes to catch all the flies.'

The sense of cultural elements that shape identities was included in the participants' narrations of various cultural elements that they identify with. When answering the question what they would like to send to artists from the other participating communities, one participant from Murmansk said: 'To Rovaniemi I would send some Kazakhstan heat, maybe a couple of camels. I hope they don't have them there. And perhaps some Asian warmth and openness.' A participant from Finland reminisced: 'The most that I like there is the peace. There are not too many people, there are lots of lakes there and you can find quiet environment and forests if you want.' 
Two Russian participants added, in a jovial tone, thoughts about cultural elements and values that underpin local identities, or 'Russian spirit': 'I'm not sure how to say this. Like vodka, balalaika and a bear!' Also: 'A bit of our Russian crazy, our ease and joy'; 'Courage and openness, or honesty. Some kind of sincerity, but also courage. Not to be afraid of being open;' and 'Perhaps, just some Russian spirit.'

Finally, a Turkish-born participant and artist that currently studies in Helsinki explained the value she attaches to stories. In this narration she alludes to the value of how stories enable her to render her personal and group identities according to the places she lives in and identifies with: 'I am from Istanbul, currently I am living in Helsinki. I like how Istanbul has lots of stories. And I like how Helsinki lets me focus on my personal story that I would like to bring you.'

\section{Mediation}

For the researchers who mediated the processes, the acts of collecting, whether they were the stories or artefact of the communities, became identity processes in themselves. The sensitivity of connecting group identities and personal identities into webs of meaning making was a delicate undertaking. Suggestions were made by the communities and researchers alike, but the process remained fragile in the sense that some (in)activities could abruptly interrupt the cycles of sharing, enactment and meaning making. However, the processes continued due to the stories and conversations the participants established in their local groups and wanted to explore amongst faraway communities on the 'edges'.

This diagram (Figure 5) is informed by Weick's (1995) theoretical framework for virtual sense-making properties that include social content, retrospect, personal identity, salient cues, ongoing events, plausibility and enactment amongst teams (Nemiro, Beyerlein, Bradley \& Beyerlein, 2008). The challenges for virtual teams can be summarised as follows:

1. the coordination of effective conversations must be designed to create meaning from relationships;

2. cultural diversity is important to the establishment of identities and roles;

3. access to information is crucial for shared understanding and meaning making;

4. the interpretation of salient cues is essential to continued actions and conversations;

5. ongoing events drive both face-to-face and virtual teams, but the demands of physical workplaces are not always evident;

6. plausibility depends on information sharing in social context, retrospect, salient cues, language and cultural understanding; and

7. enactment (the process of acting on something) follows understanding and meaning making. (Nemiro, Beyerlein, Bradley \& Beyerlein, 2008) 
The diagram (Figure 5) illustrates the virtual, and digitally enabled, process for mediation that came about in the arts activity 'Conversations'. The model suggested in Figure 5 evolved from the analysis of the case study and the experiences that derived from mediation processes in Margin to Margin.

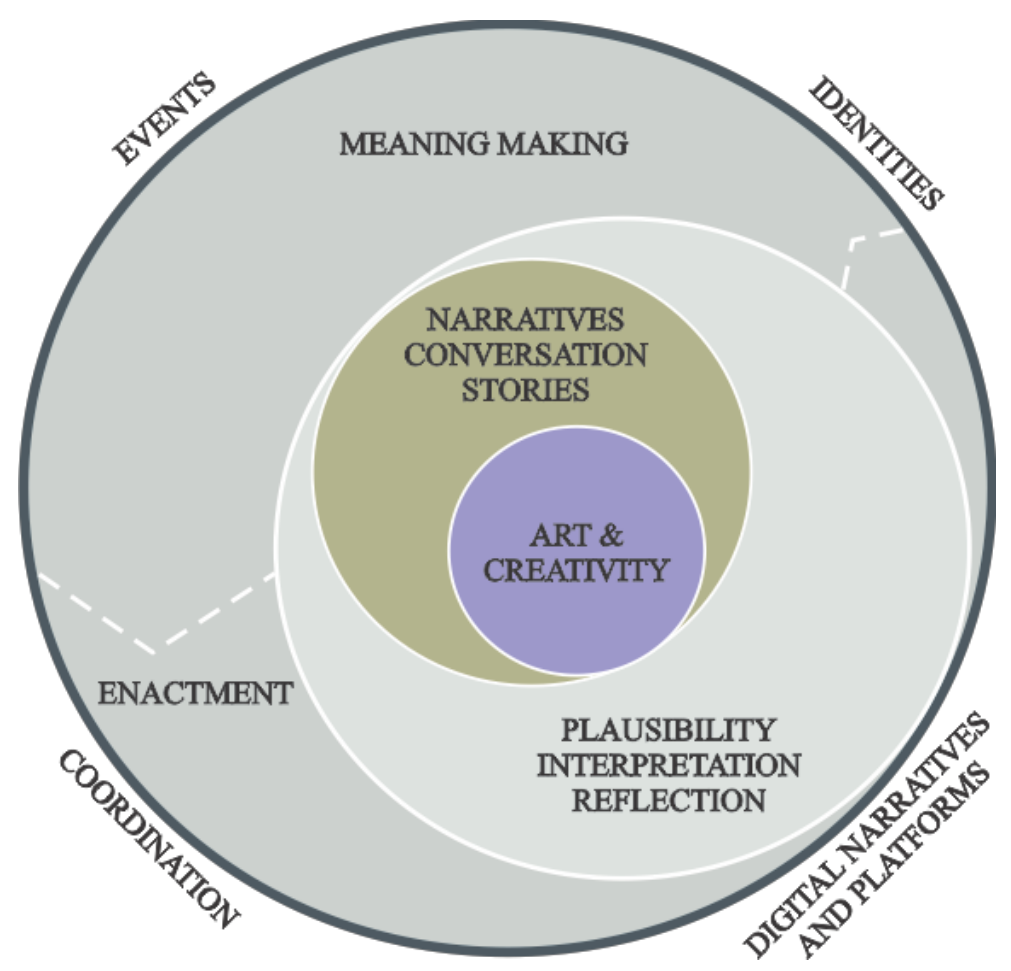

Figure 5: Virtual Mediation.

Interpreted from the centre, the diagram illustrates connections between art activities and creativity, narratives and conversation to plausible interpretations and reflections on actions and events. Once this sequence of events is stimulated and enabled, enactment and meaning making is the next step in the sequence of events. However, this step is crucial as it depends on the interaction of meaning making and enactment. This means that once art, or creativity, and narrativity leads to plausibility, meaning making and enactment follows. This process represents empowerment, because once the artist is empowered through this sequence of events, she is able to participate in coordinated events that lead to the strengthening and formations of identities that can be expressed via digital and narrative platforms. This is an inside-out process that is dynamic and offers new possibilities. This process was evident in 'Conversations', but it also illustrates the ethical process of radical inclusion that involves all stakeholders in shared dialogue. Therefore, this model guides virtual arts-based project mediation for digital outreach in both urban and regionally-situated marginalised communities.

Interpreted from the outside, this model shows how coordination, related events and identities that determine digital narratives and platforms from the outside, thus dominant to the reflective, art and narrative approaches, impacts on the arts and creativity. This impact is stagnant, and it ends, most probably, in an art product that is 
determined by outside and dominant narratives. The approach of radical inclusion, or the bottom-up approach, is illustrated as an inside out approach in this diagram. The dynamic creation of new possibilities in art, stories and plausibility (also interpretation and reflection) lead to the dynamic interaction of meaning making and enactment, or empowerment. As a result, it also leads to the empowerment of coordination processes, events and identity formations that are expressed, in the case study of 'Conversations', in physical and virtual actions and digital platforms.

\section{Conclusion}

This article set out to conceptualise a model for guiding virtual arts-based project mediation for digital outreach in both urban and regionally situated marginalised communities. It based itself on the three-year experience of mediation by the artistresearchers who collaborated with remote communities in Australia, Finland, Russia and Namibia within the scope of Margin to Margin. Virtual mediation was explicated through the overall processes of this project with the specific examples from the case study 'Conversations' that is of a particular interest to the study due to its initiation by the research participants themselves who sought connectivity and belonging to a wider global community of artistic practice.

In practical terms, the principles of mediation in the project relied on a number of digital tools and processes. Photographic, audio and video equipment allowed for quality documentation with both data-capturing and aesthetic purposes, while also helping to create spaces of dedicated and empathic narrative sharing. The employed digital tools varied between social media platforms, email, messengers, website and blog, and cloud storage platforms. All these aided the two important goals of the project: keeping the process transparent throughout all of its stages and recreating the encounters online for the participants to revisit and the audiences to experience.

The article inquired about the ways to connect to, and coordinate collaborations with, geographically remote communities. As has been outlined in 'Digital mediation and facilitation' and throughout the article, remoteness can be overcome through digital means, but in-person activities are crucial for establishing researcher-participant empathy within the communities. Thus, initial outreach can be achieved through virtual mediation that also enables the continuation of the established connection.

It was also concerned with how to maintain, in the long term, established empathy with communities of research. The answer to this question lies in understanding of empathy within or without digital contexts. As elaborated in a framework for empathy that resulted from analysis and the encounters within Margin to Margin (Miettinen, Sarantou \& Akimenko, 2016b), empathy within communities of research is not a given, but an ongoing process. Once formed, it requires ongoing activities and revision of interest and agency, much like the ethical issues of informed consent (Akimenko, Sarantou, Escudeiro \& Miettinen, 2017). The complexity of dealing with real feelings and sentiments that come through the participants' narratives and making processes should be acknowledged in mediation. The project encompassed many continuous activities 
after the actual in-person encounters through mediation between physical and digital spaces (such as exhibitions and online platforms).

While the methodology of the project was planned by the researchers with the objectives of connectivity and outreach to remote communities, the actual field situations uncovered these same objectives within the communities themselves. As exemplified through the art activity of 'Conversations' the concept of (digital) inclusion was intuitively sought by those who were less familiar with this concept. 'Conversations' presented a good example of the ethical approach of radical inclusion (Akimenko, 2018), or the so-called bottom-up approach (e.g., Sabatier, 1986), but it also illustrates the need for digital participation amongst geographically marginalised communities to share experiences, their stories and art. Additionally, this case study illustrated that the acts of identifying with somethings and not with others, sensemaking through narrations and stories, practical digital and physical representations, may lead to meaning making and enactment. In other words, 'Conversations' illustrated, in a practical sense, how empowerment works, namely, the self-empowerment that acts from within towards outward expressions.

As the project neared its end, the researchers realised that one of the shortcomings of the project was the lack of resources to establish a digital platform such as a Webdoc. This kind of platform could enable an improved digital environment for storing, dissemination, and representation of data such as digital artefacts and stories. The digital resources and on-line tools that were included in the planning and inception of the project were widely used digital applications, such as social media, online platforms and real-time document collaboration platforms, which improved the communication and connectedness within the project. This means that communities were able to communicate freely, randomly and in organised ways, amongst themselves and with the researchers to share and arrange activities and events. No purpose-built digital tools were used, which allows an opportunity for further development next to planning a perhaps more ambitious and purpose-built technological platform that can better accommodate the needs of the communities and researchers alike. Such a platform would need careful consideration of privacy, online security and intellectual property rights of all participating artists and makers. 


\section{References}

Alavi, M., \& Tiwana, A. (2002). Knowledge integration in virtual teams: The potential role of KMS. Journal of the Association for Information Science and Technology, 53(12), 1029-1037.

Akimenko, D. (2018). Narrative Spaces: On identity work and placeness through arts-based narrative practices. (PhD Thesis). University of Lapland, Rovaniemi, Finland.

Akimenko, D., Sarantou, M., Escudeiro, N., \& Miettinen, S. (2017). iDoc: A Technology Tool as a Platform for Exploring Data. In Proceedings of the 29th Australian Conference on Human-Computer Interaction, Brisbane, Australia: OzCHI.

Akimenko, D. \& Kuure, E. (2017). Narrative Identities in Participatory Art and Design Cases. Conference proceedings '7th Nordic Design Research Conference Nordes 2017 Design+Power'. Retrieved from www.nordes.org/nordes2017/assets/full_papers/ nordes17a-sub1031-cam-i26 AKIMENKO_v2.pdf

Akimenko, D., Sarantou, M., \& Miettinen, S. (2017). Narrating Identities Through Art-making on the Margins: The Case of Two Workshops in the Arctic. In L. Heininen, H. ExnerPirot, \& J. Plouffe (Eds), Arctic Yearbook 2017. Akureyri, Iceland: Northern Research Forum.

Berg, B. L. (1989). Qualitative research methods for the social sciences. New York: Allyn and Bacon.

Burnard, P. (1991). A method of analysing interview transcripts in qualitative research. Nurse education today, 11(6), 461-466.

Curşeu, P. L., Schalk, R., \& Wessel, I. (2008). How do virtual teams process information? A literature review and implications for management. Journal of Managerial Psychology, 23(6), 628-652.

Farkhatdinov, N. (2014). Beyond Decoding: Art Installations and Mediation of Audiences. Music and Arts in Action, 4(2), 52-73.

hooks, bell. (1989). Choosing the Margin as a Space of Radical Openness. In Yearning: Race, Gender, and Cultural Politics (pp. 203-209). Oxfordshire: Routledge.

Leavy, P. (2015). Method Meets Art: Arts-based Research Practice. New York: The Guilford Press.

McAdams, D. P., \& McLean, K. C. (2013). Narrative Identity. Current Directions in Psychological Science, 22(3), 233-238. doi: 10.1177/0963721413475622

Miettinen, S., Akimenko, D., Sarantou, M., Escudeiro, N., \&. Wallius, T. (2017). Naisia Maailman Laidalla (Women from the Edges of the World). Finland: Helinä Rautavaara Museum.

Miettinen, S., Sarantou, M., \& Akimenko, D. (2016a). Narrative-based Art as Means of Dialogue and Empowerment. Conference proceedings Mediations: Art \& Design Agency and Participation in Public Space. London: Royal College of Art.

Miettinen, S., Sarantou, M., \& Akimenko, D. (2016b). Collaborative art and storytelling as an empowering tool for service design: South Australian case study. In P. Rytilahti, S. Miettinen (Eds.), For profit, for good: Developing organizations through service design. Rovaniemi, Finland: University of Lapland Press.

Nemiro, J., Beyerlein, M. M., Bradley, L., \& Beyerlein, S. (Eds.) (2008). The handbook of high performance virtual teams: A toolkit for collaborating across boundaries. San Francisco: John Wiley \& Sons. 
Nichols, B. (2017). Introduction to documentary. Bloomington: Indiana University Press.

Sabatier, P. A. (1986). Top-Down and Bottom-Up Approaches to Implementation Research: a Critical Analysis and Suggested Synthesis. Journal of Public Policy, 6(1), 21-48. doi: $10.1017 / \mathrm{S} 0143814 \mathrm{X} 00003846$

Sarantou, M. A., Kontio, T., \& Miettinen, S.A. (2017). The Hero's Journey: An art-based method in social design. Conference proceedings The Art of Research IV, Aalto University, Helsinki.

Sarantou, M. A., \& Miettinen, S. A. (2017). The connective role of improvisation in dealing with uncertainty during invention and design processes. In E. Bohemia, C. de Bont, \& L. S. Holm (Eds.), Conference Proceedings of the Design Management Academy Vol. 4 (pp. 1171-1186). London: Design Management Academy. doi: 10.21606/dma.2017.

Sarantou, M. A. (2014). Namibian narratives: Postcolonial identities in craft and design. (PhD Thesis - Visual Arts). University of South Australia, School of Art, Architecture and Design, South Australia.

Sarantou, M. A. (2017). Laps as complex and intimate spaces. In J.C. Ashton (Ed.), Museums and Feminism, Vol. 1, (pp. 126-153). Museums Etc.: Edinburgh and Cambridge.

Soja, E. W. (1996). Thirdspace: Journeys to Los Angeles and Other Real-and-Imagined Places. Massachusetts, USA: Blackwell Publishing.

Somers, M. R. (1994). The narrative constitution of identity: A relational and network approach. Theory and Society, 23, 605-649.

Ricoeur, P. (1992). Oneself as Another. Chicago: University of Chicago Press.

Weick, K. E. (1995). Sensemaking in organizations, Vol. 3. New York: Sage.

Weick, K. E., Sutcliffe, K. M., \& Obstfeld, D. (2005). Organizing and the process of sensemaking. Organization science, 16(4), 409-421.

Wenger, E., McDermott, R. A., \& Snyder, W. (2002). Cultivating communities of practice: A guide to managing knowledge. Boston: Harvard Business Press. 